УДК 336.662, 330.322; JEL R11, D9

DOI: $10.17223 / 22229388 / 25 / 3$

\section{T.М. Зорина}

\section{ИНВЕСТИЦИОННЫЙ КЛИМАТ РЕГИОНА}

Дана оценка инвестициионной привлекательности $u$ инвестиционного климата региона. Рассмотрены финансовые и нефинансовые механизмы стимулирования инвестиционной деятельности. Выделены отраслевые приоритеты инвестиционного развития региона, действуюшие инвестиционные площуадки и реализуемые инвестиционные проекты. Предложены меры по улучиению инвестиционного климата.

Ключевые слова: инвестииионный климат, инвести ционная привлекательность, инвестиции в основной капитал, инвестиичонный потенциал, кластеры, инвестиционные проекты, финансовые и нефинансовые механизмы стимулирования инвестиционной деятельноcmu.

Вопрос об инвестиционном климате в РФ актуален в настоящее время в связи с вводом экономических санкций. Вывести Россию на передовые позиции в мировой экономике способны только инвестиции. Именно активизация инвестиционной деятельности - это залог экономического роста как страны, так и ее регионов.

Инвестиционный климат региона - это совокупность финансовых, социально-экономических, политических, географических и организационноправовых факторов, привлекающая либо отталкивающая инвесторов. Поэтому при оценке инвестиционного климата необходимо учитывать эко- номические условия; региональную инвестиционную политику, отражающую степень поддержки иностранных инвестиций; институциональную среду инвестиционного процесса [1. C. 262].

Наряду с существованием объективных заданных условий и предпосылок инвестиционной деятельности (географическое положение, природные богатства, уровень развития производства и социальной инфраструктуры, уровень политической стабильности) необходимо учитывать и деятельность инвесторов в этих условиях, процесс и результаты которой характеризуются положением и интересами самих инвесторов.

Инвестищионную привлекательность региона будем рассматривать как объективную заданную составляющую инвестиционного климата, совокупность объективных возможностей и ограничений, обусловливающих интенсивность привлечения инвестиций в основной капитал региона. Инвестиционная привлекательность региона включает две составляющие: инвестиционный потенциал региона, отражающий объективные возможности региона по привлечению инвестиций, а также инвестиционные риски региона, играющие роль объективных ограничений и характеризующие вероятность менее эффективного использования инвестиционного потенциала региона [2. С. 170].

Субъекты РФ значительно различаются между собой по объему и динамике инвестиций. Лидирующая роль в объеме инвестиций в основной капитал среди субъектов Сибирского федерального округа принадлежит Красноярскому краю, Алтайский край занимает седьмое место (табл. 1) [3. C. 150].

Таблица 1. Инвестиции в основной капитал субъектов СФО (выборочно)

\begin{tabular}{|c|c|c|c|c|c|}
\hline \multirow{2}{*}{ Год } & \multicolumn{5}{|c|}{ Инвестиции в основной капитал, млн руб. } \\
\cline { 2 - 6 } & $\begin{array}{c}\text { Алтайский } \\
\text { край }\end{array}$ & $\begin{array}{c}\text { Новосибирская об- } \\
\text { ласть }\end{array}$ & $\begin{array}{c}\text { Кемеровская } \\
\text { область }\end{array}$ & $\begin{array}{c}\text { Красноярский } \\
\text { край }\end{array}$ & $\begin{array}{c}\text { Омская } \\
\text { область }\end{array}$ \\
\hline 2010 & 54580 & 115015 & 156519 & 266910 & 73196 \\
\hline 2011 & 70308 & 140097 & 214780 & 308588 & 88788 \\
\hline 2012 & 83853 & 161955 & 264440 & 376090 & 108570 \\
\hline 2013 & 94586 & 174595 & 215640 & 369298 & 104963 \\
\hline 2014 & 102169 & 180035,5 & 239731 & 344539 & 105786 \\
\hline & \multicolumn{7}{|c|}{ Темп роста, в \% к предыдущему году } & 110,8 & 116,8 \\
\hline 2010 & 115,3 & 107,8 & 137,4 & 114,9 & 112,3 \\
\hline 2011 & 114,5 & 112,5 & 124,6 & 115,5 & 115,8 \\
\hline 2012 & 112,1 & 105,2 & 114,0 & 94,8 & 92,7 \\
\hline 2013 & 105,2 & 102,8 & 77,6 & 87,9 & 97,5 \\
\hline 2014 & 107,7 & 95,1 & 106,4 & 95,8 & 90,8 \\
\hline 2015 & 83,2 & 72,3 & 61,9 & & \\
\hline
\end{tabular}

Оценку инвестиционного климата для привлечения инвестиционных ресурсов в реальный сектор экономики региона дает анализ инвестиций в основной капитал в разрезе форм собственности (табл. 2).
Как видно из табл. 2, в регионе наблюдается устойчивая тенденция перераспределения капитальных вложений из государственной и муниципальной преимущественно в частную форму собственности. 
Таблица 2. Инвестиции в основной капитал по формам собственности

\begin{tabular}{|l|c|c|c|c|c|c|c|c|}
\hline & \multicolumn{3}{|c|}{ млрд руб. } & \multicolumn{3}{c|}{ в \% к итогу } \\
\cline { 2 - 8 } & 2012 г. & 2013 г. & 2014 г. & 2015 г. & 2012 г. & 2013 г. & 2014 г. & 2015 г. \\
\hline $\begin{array}{l}\text { Инвестиции в ос- } \\
\text { новной капитал - } \\
\text { всего }\end{array}$ & 49446,7 & 48113,8 & 51125,9 & 50000,0 & 100,0 & 100,0 & 100,0 & 100,0 \\
\hline в том числе по & & & & & & & \\
формам собствен- & & & & & & & \\
ности: & 16067,1 & 13854,2 & 11974,8 & 11050,0 & 32,5 & 28,8 & 23,4 & 22,1 \\
государственная & 5639,0 & 7359,8 & 6657,4 & 5950,0 & 11,4 & 15,3 & 13,0 & 11,9 \\
муниципальная & 17620,2 & 16914,3 & 21409,7 & 21700 & 35,6 & 35,2 & 41,9 & 43,4 \\
частная & & & & & & & \\
смешанная россий- \\
ская
\end{tabular}

В структуре инвестиций в основной капитал доля государственной и муниципальной собственности снизилась до $34 \%$, доля смешанной российской собственности - до $3,5 \%$. Но возросли инвестиции в основной капитал в частной форме собственности с 35 до $43 \%$, заняв лидирующее положение среди других форм собственности. Пока в инвестиционном процессе региона не играет существенной роли совместная российская и иностранная формы собственности. Данное обстоятельство частично объясняется неблагоприятным инвестиционным климатом, прежде всего для иностранных инвесторов.

Зарубежные инвесторы предпочитают вкладывать средства в территории, которые характеризуются высокой платежеспособностью населения, имеют емкий рынок сбыта, отраслевую структуру экономики, развитую международную коммуникационную инфраструктуру, активную и либеральную политику региональных властей [4. C. 144].

Для улучшения инвестиционного климата и стимулирования притока иностранных инвестиционных ресурсов в регион можно выделить несколько мер, среди которых:

- формирование благоприятного национального режима для иностранных инвесторов в виде низких и прозрачных налогов, защиты прав собственности и исполнения контрактов;

- углубление экономической и социальной интеграции экономики региона в систему международных связей через выделенные стратегические направления развития региона;

- повышение инвестиционной привлекательности региона [5. С. 24].

Анализ результатов национального рейтинга инвестиционной привлекательности регионов позволяет сделать вывод о том, что исходное социально-экономическое положение региона оказывает незначительное влияние на инвестиционный климат. Инвестиционная привлекательность зависит от эффективности управления региональной экономикой и предпринимательской активности хозяйствующих субъектов, органов власти и усилий, которые они предпринимают.
Формы и методы, которые используют субъекты РФ, стремясь повысить инвестиционную привлекательность, содержат практически идентичную систему инструментов. Это связано с тем, что региональная инвестиционная политика формируется по принципу дополнения и улучшения существующих федеральных законов. Так, региональные нормативные акты предусматривают:

- формирование и использование инвестиционного фонда;

- предоставление налоговых льгот и субсидий;

- обеспечение гарантий по кредитам субъектам предпринимательства;

- создание приоритетных статусов инвестиционным проектам;

- равную защиту прав, интересов и имущества инвесторов и пр.

Самыми распространенными региональными законодательными актами являются законы:

- об инвестиционной деятельности региона;

- о государственной поддержке инвестиционной деятельности на территории региона;

- о государственном регулировании инвестиционной деятельности на территории региона.

Данные акты относят к числу «рамочных законов», регулирующих инвестиционную деятельность субъекта. Подобные документы разработаны и в регионах СФО, Алтайский край не является исключением.

В регионе, в основном, акцент делается на двух группах инструментов стимулирования инвесторов: финансовых и нефинансовых [6].

К финансовым механизмам стимулирования инвестиционной деятельности в крае относятся:

- субсидирование за счет средств краевого бюджета части банковской процентной ставки по кредитам (в 2016 г. краевым бюджетом выделено 5,0 млн руб.);

- субсидирование за счет средств краевого бюджета налога на имущество организаций и налога на прибыль;

- прямое финансирование за счет регионального инвестиционного фонда (в 2016 г. установлен объем регионального инвестиционного фонда Алтайского края до 562,0 млн руб.); 
- субсидии на поддержку отдельных отраслей растениеводства и животноводства;

- субсидирование части затрат субъектов предпринимательства, связанных с приобретением оборудования в целях создания и (или) развития производства товаров (выполнения работ, оказания услуг);

- гранты губернатора Алтайского края для поддержки инновационной деятельности машиностроительных предприятий края, а также гранты на реализацию проектов в приоритетных сферах экономики;

- кредитование субъектов предпринимательства с использованием средств фонда микрозаймов (на начало 2016 г. активы НМО «Алтайский фонд микрозаймов» составляют 371,5 млн руб.);

- кредитование субъектов предпринимательства с использованием средств гарантийного фонда (капитализация НО «Алтайский гарантийный фонд» на сегодняшний день составляет более 638,4 млн руб.);

- использование средств Алтайского краевого лизингового фонда (предполагаемый объем финансирования в 2016 г. - 255 млн руб.).

К нефинансовым мерам поддержки инвестиционной деятельности относятся:

- передача в залог имущества казны Алтайского края, в том числе акций (долей) хозяйственных обществ, для обеспечения обязательств организаций при осуществлении инвестиционной деятельности;

- возможность выкупа земельного участка в частную собственность на территории особой экономической зоны туристско-рекреационного типа «Бирюзовая Катунь» и на территории игорной зоны «Сибирская монета».

Отметим, что на стыке финансовых и нефинансовых инструментов в регионе существуют и прочие меры по повышению инвестиционной привлекательности: имущественная поддержка КГБУ «Алтайский бизнес-инкубатор» и МБУ «Бийский бизнес-инкубатор»; Инвестиционный портал региона, на который возложена миссия презентации инвестиционного потенциала края; созданы и функционируют институты развития КАУ «Алтайский центр инвестиций и развития», КГБУ «Алтайский центр кластерного развития», КГБУ «Алтайский центр инноваций социальной сферы», КАУ «Алтайский центр государственно-частного партнерства и привлечения инвестиций».

В настоящее время на территории региона действуют семь инвестиционных площадок: автотуристический кластер «Золотые ворота», игорная зона «Сибирская монета», индустриальный парк «Новоалтайск Южный», некоммерческое партнерство «Инновационно-производственный технологический парк «Бийск», ОЭЗ туристскорекреационного типа «Бирюзовая Катунь», туристско-рекреационный кластер «Белокуриха» и туристско-экскурсионный развлекательный парк «Сибирь изначальная».

В целях улучшения инвестиционного климата в регионе принята «Стратегия социально-экономического развития Алтайского края до 2025 года», где на основе проведенного анализа конкурентоспособности экономики региона и комплексной оценки его потенциала выявлены конкурентные преимущества и внутренние сдерживающие факторы, определяющие его инвестиционную привлекательность а также выделены отраслевые приоритеты инвестиционного развития региона. К данным приоритетам относятся: производство и переработка сельскохозяйственного сырья; биотехнологии; синтез лекарственных средств и пищевых добавок; машиностроение; химия и новые материалы; индустрия наносистем и материалов; новые энергосберегающие строительные материалы и высокоэффективные технологии для производства строительных материалов, изделий и конструкций, систем инженерного обеспечения домов; информационные системы и технологии; охрана окружающей среды и рациональное природопользование; энергетика и энергосбережение [7].

Накопленные в регионе природно-ресурсный, экономический, туристско-рекреационный, инфраструктурный и инновационный потенциалы создали предпосылки для создания кластеров: аграрного машиностроения, биофармацевтического, туристического, полимерно-композитного, энергомашиностроения и энергоэффективных технологий.

Сегодня в регионе реализуются инвестиционные проекты, которые по виду экономической деятельности можно разделить на три категории: промышленное производство; сельское хозяйство; туризм и рекреация (табл. 3) [8].

Таблица 3. Реализуемые основные инвестиционные проекты региона

\begin{tabular}{|c|c|c|c|}
\hline Реализуемые инвестиционные проекты & Компании-инвесторы & $\begin{array}{c}\text { Начало } \\
\text { реализа- } \\
\text { ции }\end{array}$ & $\begin{array}{c}\text { Объем инвести- } \\
\text { ций, млн руб. }\end{array}$ \\
\hline 1 & 2 & 3 & 4 \\
\hline \multicolumn{4}{|c|}{ Промышленное производство } \\
\hline $\begin{array}{l}\text { Строительство производственного комплекса } \\
\text { для производства кормов, химикатов, биотопли- } \\
\text { ва и пищевых добавок }\end{array}$ & $\begin{array}{c}\text { OОО «Аванкор»/компания } \\
\text { ASC }\end{array}$ & 2014 & 35,0 \\
\hline $\begin{array}{l}\text { Техническое перевооружение и модернизация } \\
\text { бронекорпусного и холодноштамповочного } \\
\text { производства }\end{array}$ & Минпромторг России & 2014 & 70,9 \\
\hline
\end{tabular}


Окончание табл. 3

\begin{tabular}{|c|c|c|c|}
\hline 1 & 2 & 3 & 4 \\
\hline $\begin{array}{l}\text { Реконструкция для создания производства окто- } \\
\text { гена }\end{array}$ & $\begin{array}{l}\text { Министерство экономического } \\
\text { развития РФ }\end{array}$ & 2013 & 857,3 \\
\hline $\begin{array}{l}\text { Создание производства светодиодной продукции } \\
\text { и электронных устройств }\end{array}$ & ФКП «Бийский олеумный завод» & 2013 & 150,0 \\
\hline Комплекс по производству извести & ОАО ПКФ «Силикатчик» & 2012 & 224,7 \\
\hline $\begin{array}{l}\text { Реконструкция и техническое перевооружение } \\
\text { производства сырьевого компонента паранитро- } \\
\text { толуола (ПНТ) для создания арамидных волокон }\end{array}$ & $\begin{array}{l}\text { Департамент промышленности } \\
\text { обычных вооружений, боеприпа- } \\
\text { сов и спецхимии Министерства } \\
\text { промышленности и торговли }\end{array}$ & 2012 & 100,0 \\
\hline $\begin{array}{l}\text { Строительство Алтайской конденсационной } \\
\text { электрической станции }\end{array}$ & $\begin{array}{l}\text { ООО «Алтайская конденсацион- } \\
\text { ная электрическая станция» }\end{array}$ & 2011 & 60185,0 \\
\hline $\begin{array}{l}\text { Строительство Корбалихинского полиметалличе- } \\
\text { ского рудника по добыче руды подземным спо- } \\
\text { собом }\end{array}$ & $\begin{array}{l}\text { ОАО «Уралэлектромедь», } \\
\text { ОАО «Сибирьполиметаллы» }\end{array}$ & 2008 & 10000,0 \\
\hline \multicolumn{4}{|c|}{ Сельское хозяйство } \\
\hline $\begin{array}{l}\text { Алтайское мясо: } 10 \text { племенных генетических } \\
\text { площадок «Корова и теленок» по } 2400 \text { голов } \\
\text { маточного поголовья и } 35 \text { голов племенных бы- } \\
\text { ков абердинагусской породы; } 5 \text { откормочных } \\
\text { площадок по откорму КРС общим поголовьем до } \\
1500 \text { голов; современный мясоперерабатываю- } \\
\text { щий комбинат }\end{array}$ & ООО АПО «Казачья станица» & 2014 & 6100,0 \\
\hline $\begin{array}{l}\text { Комплекс по переработке молока производитель- } \\
\text { ностью до } 150 \text { т/сут (производство твердых и } \\
\text { плавленых сыров, масла, творога) }\end{array}$ & $\begin{array}{l}\text { ООО «Новоромановский масло- } \\
\text { сырзавод» }\end{array}$ & 2013 & 220,0 \\
\hline $\begin{array}{l}\text { Строительство комплекса по содержанию и от- } \\
\text { корму КРС мясного направления до } 5000 \text { коров в } \\
\text { Каменском районе }\end{array}$ & ООО «Откормочник-1» & 2013 & 156,5 \\
\hline $\begin{array}{l}\text { Молочно-товарная ферма на } 960 \text { голов КРС и цеха } \\
\text { по производству концентрированных кормов }\end{array}$ & ООО «Акуловское» & 2013 & 100,0 \\
\hline $\begin{array}{l}\text { Оросительная система для полива кормовых } \\
\text { культур с целью увеличения объемов производ- } \\
\text { ства и качества кормов, обеспечения животно- } \\
\text { водческого комплекса кормами собственного } \\
\text { производства }\end{array}$ & ОАО «им. Гастелло» & 2012 & 100,0 \\
\hline Строительство цеха по приготовлению кормов & ООО «Фунтики» & 2012 & 63,6 \\
\hline $\begin{array}{l}\text { Оросительная система для полива кормовых } \\
\text { культур }\end{array}$ & ОАО «Свердловское» & 2012 & 55,0 \\
\hline $\begin{array}{l}\text { Зерноочистительный комплекс с зерносушилкой } \\
\text { и складом силосного типа }\end{array}$ & СПК «Знамя Родины» & 2011 & 50,0 \\
\hline \multicolumn{4}{|c|}{ Туризм и рекреация } \\
\hline Оздоровительный центр & ООО «Водный мир» & 2011 & 434,0 \\
\hline $\begin{array}{l}\text { Панто-оздоровительный центр с горнолыжным } \\
\text { комплексом «Никольское» }\end{array}$ & ООО «Брюс» & 2009 & 109,0 \\
\hline Туристический комплекс «Рыбацкая деревня» & ЗАО «Курорт Белокуриха» & 2009 & 22,0 \\
\hline $\begin{array}{l}\text { Строительство крупного туристского комплекса } \\
\text { на } 3500 \text { мест размещения на территории «ОЭЗ } \\
\text { ТРТ «Бирюзовая Катунь» }\end{array}$ & $\begin{array}{l}\text { Администрация Алтайского } \\
\text { края/Управление Алтайского края } \\
\text { по развитию туристско- } \\
\text { рекреационного и санаторно- } \\
\text { курортного комплексов }\end{array}$ & 2007 & 30000,0 \\
\hline
\end{tabular}

Регион по итогам 2015 г. занимает 32-е место по уровню инвестиционного риска (37-е в 2014 г.) и 26-е - по уровню инвестиционного потенциала (27-е в 2014 г.) в рейтинге ведущего агентства «Эксперт РА». Очевидно, что по сравнению с 2014 г. Алтайский край немного улучшил свой инвестиционный рейтинг.

Но, несмотря на работу, которые ведут региональные власти по повышению инвестиционной привлекательности края, проблемы существуют, среди них:

- недостаточное развитие финансовокредитной системы и фондового рынка края и недостаточное его использование для привлечения инвестиций;
- низкий уровень капитализации бизнеса, незначительное количество инвестиционно-привлекательных компаний;

- низкий уровень вовлеченности населения и хозяйствующих субъектов в инвестиционные процессы, происходящие в крае;

- высокая зависимость края от крупных корпоративных интересов;

- недостаточная информационная открытость хозяйствующих субъектов Алтайского края;

- несовершенство земельных отношений и земельного рынка и пр.

Таким образом, к мерам, стимулирующим приток иностранных инвестиций в регион (указанных выше) и благоприятно влияющим на инвестиционный климат, можно добавить следующее: 
- принятие и реализация инвестиционной стратегии в рамках внедрения Стандарта инвестиционного климата в регионах;

- увеличение финансовых и нефинансовых механизмов повышения инвестиционной привлекательности, таких как инвестиционный налоговый кредит, рассрочка налоговых платежей, создание венчурного фонда;

- создание современной банковской системы в регионе;

- снижение и ликвидация административных барьеров;

- развитие малого и среднего предпринимательства;

- продвижение инвестиционных возможностей региона.

Данные мероприятия, на наш взгляд, будут способствовать повышению инвестиционной привлекательности и улучшению инвестиционного климата региона.
Литература

1. Котуков А.А. К вопросу исследования понятия «инвестиционный климат» // Проблемы современной экономики. 2008. № 4. C. 261-265.

2. Зорина T.M. Реализация стратегических приоритетов в бизнес-структурах регионов // Экономика и управление: анализ тенденций и перспектив развития. 2012. № 1. С. 169-173.

3. Алтайский край в цифрах. 2010-2014: Крат. стат. сборник // Территориальный орган Федеральной службы государственной статистики по Алтайскому краю. Барнаул. 2015. 252 с.

4. Зорина Т.М. Оценка промышленного развития региона (на материалах Алтайского края) // Социально-экономическое развитие общества в координатах XXI в.: традиции и инновации: сборник статей / Алтайская академия экономики и права. 2014. C. $139-145$.

5. Киселева О.В. Политика привлечения инвестиций в регион // Регионология. 2013. № 1. С. 21-27.

6. Инвестиционный портал Алтайского края http:// invest.alregn.ru

7. Официальный сайт Главэкономики http://www.econom22.ru

8. Официиальныци сайт Алтайского края http://www.altairegion22.ru 